\title{
Single Valued Neutrosophic Signedgraphs
}

\author{
Seema Mehra \\ Department of Mathematics, \\ M.D. University, \\ Rohtak - 124001, Haryana, India.
}

\author{
Manjeet Singh \\ Department of Mathematics, \\ K.L.P. College, \\ Rewari - 123401, Haryana, India.
}

\begin{abstract}
Motivated by the notion of single valued neutrosophic graphs defined by Broumi, Talea, Bakali and Smarandache[2] and notion of intuitionistic fuzzy signed graphs defined by Mishra and $\mathrm{Pal}[8]$, we introduce the concept of single valued neutrosophic signed graphs and examine the properties of this new concept and examples.
\end{abstract}

\section{Keywords}

Single valued neutrosophic graph, single valued neutrosophic signed graph, complementry single valued neutrosophic signed graph.

\section{INTRODUCTION}

In 1953, Harary[7] introduced the notion of balance of a signed graph. After that Cartwright and Harary [3] introduced the notion of signed graph as an application with the problems in social psychology. Afterward many authors [14] established sequential results on this concept. Nirmala and Prabavathi [8] introduced signed fuzzy graph. Recently, Mishra and $\mathrm{Pal}[8]$ introduced the concept of intuitionistic fuzzy signed graph and obtained some properties over it. In 2016, Broumi, Talea, Bakali and Samarandache[2] defined single valued neutrosophic graphs and study some certain types of single valued neutrosophic graphs with their properties. Motivated by the notion of single valued neutrosophic graphs defined by Broumi, Talea, Bakali and Smarandache[2] and notion of intuitionistic fuzzy signed graphs defined by Mishra and $\mathrm{Pal}[8]$, we introduce the concept of single valued neutrosophic signed graphs and examine the properties of this new concept and examples.

\section{PRELIMINARIES}

Definition 2.1 [10]. Let $\mathrm{X}$ be a space of points (objects) with generic elements in $\mathrm{X}$ denoted by $\mathrm{x}$; then the neutrosophic set $\mathrm{A}$ is an object of the form

$\mathrm{A}=\{\langle\mathrm{x}: \mathrm{TA}(\mathrm{x}), \operatorname{IA}(\mathrm{x}), \operatorname{FA}(\mathrm{x})\rangle,, \mathrm{x} \in \mathrm{X}\}$

where the functions $T, I, F: X \rightarrow]-0,1+[$ define respectively the a truth-membership function, an indeterminacymembership function, and a falsity-membership function of the element $\quad \mathrm{x} \in \mathrm{X}$ to the set $\mathrm{A}$ with the condition

$0 \leq \mathrm{TA}(\mathrm{x})+\mathrm{IA}(\mathrm{x}) \quad+\mathrm{FA}(\mathrm{x}) \quad \leq 3+$

The functions $\mathrm{TA}(\mathrm{x}), \operatorname{IA}(\mathrm{x})$ and $\mathrm{FA}(\mathrm{x})$ are real standard or nonstandard subsets of $]-0,1+[$.

Definition 2.2 [14]. Let $\mathrm{X}$ be a space of points (objects) with generic elements in $\mathrm{X}$ denoted by $\mathrm{x}$. A single valued neutrosophic set A (SVNS A) is characterized by truthmembership function $\mathrm{TA}(\mathrm{x})$, an indeterminacy-membership function $\operatorname{IA}(\mathrm{x})$, and a falsity-membership function $\mathrm{FA}(\mathrm{x})$.

For each point $\mathrm{x}$ in $\mathrm{X}, \mathrm{TA}(\mathrm{x}), \mathrm{IA}(\mathrm{x}), \mathrm{FA}(\mathrm{x}) \in[0,1]$.
$\mathrm{A}=\{\langle\mathrm{x}: \mathrm{TA}(\mathrm{x}), \mathrm{IA}(\mathrm{x}), \mathrm{FA}(\mathrm{x})\rangle,, \mathrm{x} \in \mathrm{X}\}$

Definition 2.3. A fuzzy graph $G(\sigma, \mu)$ is said to be a fuzzy signed graph if there is a mapping $\eta: E \rightarrow\{+,-\}$ such that each edge signed to $\{+,-\}$ or all nodes and edges assigned to $\{+,-\}$. When we assign $\{+$ or -$\}$ to each of the nodes called vertex signed fuzzy graph.

For assignment of sign to any edge we follow some rule, according to the problems or relations between the objects we define some $\alpha$ after it we take an $\alpha$-cut for the set of edges, than we assign positive or negative sign to the edges appear in $\alpha$-cut set and alternate sign for those edges which are not in $\alpha$ cut set.

In the following fuzzy graph shown in figure 1, we assume $\alpha$ $=.4$, thus $\alpha$-cut set for edge set contain only two edges v1v2 and v1v4. So we assign positive sign to these edges and for remaining we assigned it by negative sign.
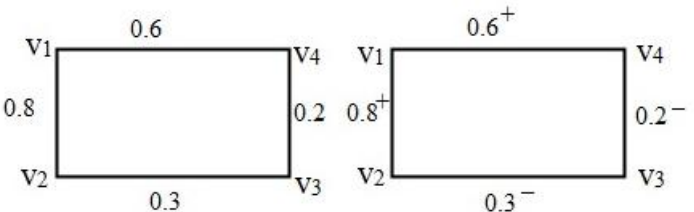

Figure 1: Fuzzy graph and its signed graph

Definition 2.4:- Sum of the membership values of all incident positive edge to $\mathrm{v}$ is known as positive degree of any vertex $\mathrm{v}$, i.e. $\operatorname{deg}+[\sigma(v)]=\sum_{\mu^{+}\left(v, v_{i}\right) \in E} \mu^{+}\left(v, v_{i}\right)$.

Similarly, by negative degree we mean

$\operatorname{deg}-[\sigma(v)]=\sum_{\mu^{-}\left(v, v_{i}\right) \in E} \mu^{-}\left(v, v_{i}\right)$.

And sign degree of any vertex $\mathrm{v}$ is difference between $\operatorname{deg}+[\sigma(\mathrm{v})]$ and $\operatorname{deg}-[\sigma(\mathrm{v})]$, it is denoted by $\operatorname{sdeg}(\mathrm{v})$,

i.e. $\operatorname{sdeg}(v)=|\operatorname{deg}+[\sigma(v)]-\operatorname{deg}-[\sigma(v)]|$.

Example 1. An example to calculate sign degree of all nodes of a fuzzy signed graph.

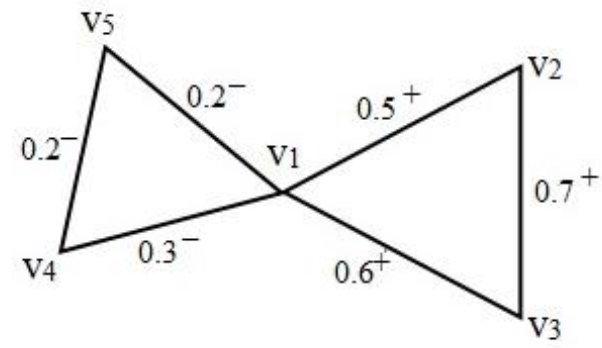

Figure 2: Signed fuzzy graph 
Sign degree of vertices for signed fuzzy graph shown in figure 2 are

$$
\begin{aligned}
& \operatorname{sdeg}\left(\mathrm{v}_{1}\right)=|(0.5+0.6)-(0.2+0.3)|=|1.1-0.5|=0.6, \\
& \operatorname{sdeg}\left(\mathrm{v}_{2}\right)=|(0.5+0.7)-0|=|1.2-0|=1.2, \\
& \operatorname{sdeg}\left(\mathrm{v}_{3}\right)=|(0.6+0.7)-0|=|1.3-0|=1.3, \\
& \operatorname{sdeg}\left(\mathrm{v}_{4}\right)=|0-(0.3+0.2)|=|0-0.5|=0.5, \\
& \operatorname{sdeg}\left(\mathrm{v}_{5}\right)=|0-(0.2+0.2)|=|0-0.4|=0.4
\end{aligned}
$$

Definition 2.5 : Let $A=\left(T_{A}, I_{A}, F_{A}\right)$ and $B=\left(T_{B}, I_{B}, F_{B}\right)$ be single valued neutrosophic sets on a set $\mathrm{X}$. If $\mathrm{A}=\left(\mathrm{T}_{\mathrm{A}}, \mathrm{I}_{\mathrm{A}}, \mathrm{F}_{\mathrm{A}}\right)$ is a single valued neutrosophic relation on a set $\mathrm{X}$, then $\mathrm{A}=\left(\mathrm{T}_{\mathrm{A}}, \mathrm{I}_{\mathrm{A}}, \mathrm{F}_{\mathrm{A}}\right)$ is called a single valued neutrosophic relation on $\mathrm{B}=\left(\mathrm{T}_{\mathrm{B}}, \mathrm{I}_{\mathrm{B}}, \mathrm{F}_{\mathrm{B}}\right)$ if

$$
\begin{gathered}
\mathrm{T}_{\mathrm{B}}(\mathrm{x}, \mathrm{y}) \leq \min \left(\mathrm{T}_{\mathrm{A}}(\mathrm{x}), \mathrm{T}_{\mathrm{A}}(\mathrm{y})\right) \\
\mathrm{I}_{\mathrm{B}}(\mathrm{x}, \mathrm{y}) \geq \max \left(\mathrm{I}_{\mathrm{A}}(\mathrm{x}), \mathrm{I}_{\mathrm{A}}(\mathrm{y})\right) \text { and } \\
\mathrm{F}_{\mathrm{B}}(\mathrm{x}, \mathrm{y}) \geq \max \left(\mathrm{F}_{\mathrm{A}}(\mathrm{x}), \mathrm{F}_{\mathrm{A}}(\mathrm{y})\right) \text { for all } \mathrm{x}, \mathrm{y} \in \mathrm{X} .
\end{gathered}
$$

A single valued neutrosophic relation $\mathrm{A}$ on $\mathrm{X}$ is called symmetric if

$$
\begin{gathered}
T_{A}(x, y)=T_{A}(y, x), \\
I_{A}(x, y)=I_{A}(y, x), F_{A}(x, y)=F_{A}(y, x) \text { and } \\
T_{B}(x, y)=T_{B}(y, x), I_{B}(x, y)=I_{B}(y, x) \text { and } \\
F_{B}(x, y)=F_{B}(y, x) \text { for all } x, y \in X .
\end{gathered}
$$

Throughout this paper, we denote $\mathrm{G}^{*}=(\mathrm{V}, \mathrm{E})$ a crisp graph, and $\mathrm{G}=(\mathrm{A}, \mathrm{B})$ a single valued neutrosophic graph.

Definition 2.6[2] A single valued neutrosophic graph (SVN-graph) with underlying set $\mathrm{V}$ is defined to be a pair $\mathrm{G}=(\mathrm{A}, \mathrm{B})$ where

1. The functions $T_{A}: V \rightarrow[0,1], I_{A}: V \rightarrow[0,1]$,

$, F_{A}: V \rightarrow[0,1]$ denote the degree of truthmembership, degree of indeterminacy-membership and falsity-membership of the element $v_{i} \in V$ respectively and

$$
\begin{gathered}
0 \leq T_{A}\left(v_{i}\right)+I_{A}\left(v_{i}\right)+F_{A}\left(v_{i}\right) \leq 3 \\
\text { for all } v_{i} \in V(i=1,2, \ldots, n)
\end{gathered}
$$

2. The functions $T_{B}: E \leq V \times V \rightarrow[0,1]$,

$$
\begin{gathered}
I_{B}: E \leq V \times V \rightarrow[0,1] \text { and } \\
F_{B}: E \leq V \times V \rightarrow[0,1]
\end{gathered}
$$

are defined by

$$
\begin{gathered}
T_{B}\left(v_{i}, v_{j}\right) \leq \min \left[T_{A}\left(v_{i}\right), T_{A}\left(v_{j}\right)\right] \\
I_{B}\left(v_{i}, v_{j}\right) \geq \max \left[I_{A}\left(v_{i}\right), I_{A}\left(v_{j}\right)\right] \text { and } \\
F_{B}\left(v_{i}, v_{j}\right) \geq \max \left[F_{A}\left(v_{i}\right), F_{A}\left(v_{j}\right)\right]
\end{gathered}
$$

\begin{tabular}{|c|c|c|c|c|}
\hline & $v_{1}$ & $v_{2}$ & $v_{3}$ & $v_{4}$ \\
\hline$T_{A}$ & 0.4 & 0.5 & 0.3 & 0.2 \\
\hline$I_{A}$ & 0.2 & 0.2 & 0.5 & 0.4 \\
\hline$F_{A}$ & 0.5 & 0.3 & 0.6 & 0.3 \\
\hline & $v_{1} v_{2}$ & $v_{2} v_{3}$ & $v_{3} v_{4}$ & $v_{4} v_{5}$ \\
\hline$T_{B}$ & 0.4 & 0.3 & 0.2 & 0.1 \\
\hline$I_{B}$ & 0.2 & 0.5 & 0.5 & 0.4 \\
\hline$F_{B}$ & 0.5 & 0.6 & 0.6 & 0.5 \\
\hline
\end{tabular}

Denotes the degree of truth-membership, indeterminacymembership and falsity-membership of the edge $\left(v_{i}, v_{j}\right) \in E$ respectively, where

$$
\begin{gathered}
0 \leq T_{B}\left(v_{i}, v_{j}\right)+I_{B}\left(v_{i}, v_{j}\right)+F_{B}\left(v_{i}, v_{j}\right) \leq 3 \\
\text { for all }\left(v_{i}, v_{j}\right) \in E(i, j=1,2, \ldots, n)
\end{gathered}
$$

We call A the single valued neutrosophic vertex set of $\mathrm{V}$, $B$ the single valued neutrosophic edge set of E, respectively. Note that B is a symmetric single valued neutrosophic relation on A. We use the notation for an element of E. Thus, $\mathrm{G}=(\mathrm{A}, \mathrm{B})$ is a single valued neutrosophic graph of $\mathrm{G}^{*}=(\mathrm{V}, \mathrm{E})$ if

$$
\begin{gathered}
T_{B}\left(v_{i}, v_{j}\right) \leq \min \left[T_{A}\left(v_{i}\right), T_{A}\left(v_{j}\right)\right] \\
I_{B}\left(v_{i}, v_{j}\right) \geq \max \left[I_{A}\left(v_{i}\right), I_{A}\left(v_{j}\right)\right] \text { and } \\
F_{B}\left(v_{i}, v_{j}\right) \geq \max \left[F_{A}\left(v_{i}\right), F_{A}\left(v_{j}\right)\right] \text { for all }\left(v_{i}, v_{j}\right) \in E
\end{gathered}
$$

Example2. Consider a graph $\mathrm{G}^{*}$ such that

$\mathrm{V}=\left\{\mathrm{v}_{1}, \mathrm{v}_{2}, \mathrm{v}_{3}, \mathrm{v}_{4}\right\}, \mathrm{E}=\left\{\mathrm{v}_{1} \mathrm{v}_{2}, \mathrm{v}_{2} \mathrm{v}_{3}, \mathrm{v}_{3} \mathrm{v}_{4}, \mathrm{v}_{4} \mathrm{v}_{1}\right\}$. Let $\mathrm{A}$ be $\mathrm{a}$ single valued neutrosophic subset of $\mathrm{V}$ and let $\mathrm{B}$ a single valued neutrosophic subset of $\mathrm{E}$ denoted by

$(0.4,0.2,0.5)$ $(0.4,0.2,0.5) \quad(0.5,0.2,0.3)$

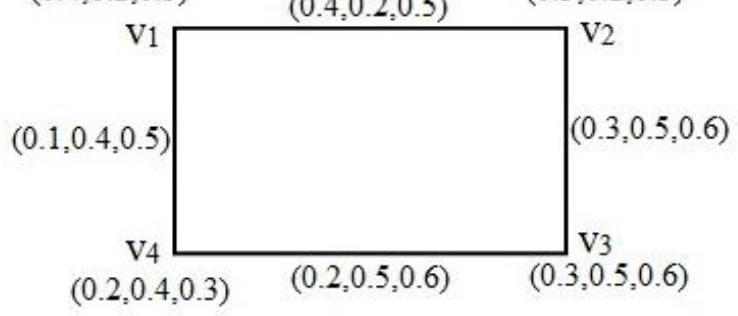

Figure 3:- G: Single valued neutrosophic graph In figure 3 ,

i. $\quad\left(v_{l}, 0.4,0.2,0.5\right)$ is single valued neutrosophic vertex or SVN-vertex.

ii. $\quad\left(v_{l} v_{2}, 0.4,0.2,0.5\right)$ is a single valued neutrosophic edges or SVN-edge.

iii. $\quad\left(v_{1}, 0.4,0.2,0.5\right)$ and $\left(v_{2}, 0.5,0.2,0.3\right)$ are single valued neutrosophic adjacent vertices.

iv. $\quad\left(v_{1} v_{2}, 0.4,0.2,0.5\right)$ and $\left.\left(v_{1} v_{4}, 0.1,0.4,0.5\right)\right)$ are single valued neutrosophic adjacent edge.

\section{SINGLE VALUED SIGNED NEUTROSOPHIC GRAPH}

Definition 3.1:- A single valued neutrosophic graph $\breve{G}$ is said to be single valued signed neutrosophic graph

if $\sigma: \mathrm{E}(\breve{\mathrm{G}}) \rightarrow\{+1,-1\}$ is a function associated from $\mathrm{E}(\widetilde{\mathrm{G}})$ of $\breve{G}$ such that each edges signed to $\{+,-\}$ or all edges and nodes are signed to $\{+,-\}$.

We assign $\mathrm{E}(\breve{\mathrm{G}}) \rightarrow\{+1,-1\}$ on the comparison basis of its truth-membership, indeterminacy-membership and falsityMembership values. If the truth-membership value is greater than both indeterminacy-membership and falsity-Membership values, we assign it positive and in reverse case we assign it negative and in case of equality we keep it unsigned.

Definition 3.2:- For a single valued neutrosophic graph any vertex is said to be positive or negative signed if 
$\sigma: V(\widetilde{G}) \rightarrow\{+1,-1\}$ is positive or negative, where $\sigma$ is a function associated from $V(\widetilde{G})$ of $\breve{G}$ on the comparison basis of truth-membership, indeterminacy-membership and falsitymembership values of $\mathrm{V}$, similar as edge sign.

A single valued signed neutrosophic graph is said to be positive if all the edges gets positive sign or only even number of edges have negative sign, basically, sign of SVSNG is determined by the product of the signs of all edges. Similarly, a SVSNG is said to be negative signed if odd number of edges of SVSNG are negative.

Lemma 3.3:- A single valued neutrosophic signed graph is a single valued neutrosophic positive signed graph if every even length cycles having all negative signed nodes.

Proof:. In the following figure 4 , if all the edges contains negative sign in even length cycle then the product of edges sign is always positive hence it is always a positive signed graph.

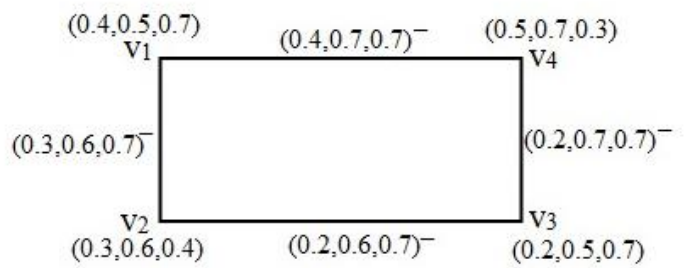

\section{Figure 4: Positive single valued signed neutrosophic graph}

Corollary 3.4:- Odd length cycle having all negative signed nodes is always a negative signed graph.

Definition 3.5:- A single valued signed neutrosophic graph is said to be balanced if every cycle of the graph have even number of negative signed edges or all positive signed edges. We say SVSNG is completely balanced if

$\sum_{i=1}^{n} T_{i}=\sum_{i=1}^{n} I_{i}=\sum_{i=1}^{n} F_{i}$ for all edges of $G$.

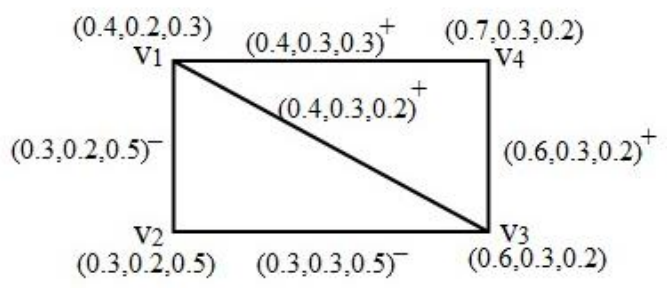

Figure 5: Balanced single valued signed neutrosophic graph

Proposition 3.6:- An odd length single valued signed neutrosophic cycle is balanced iff it contains at least one positive edge or odd number of positive edges.

Definition 3.7:- Frustration number is defined as the minimum number of edges required to remove from a graph to make a graph balanced.

In a crisp graph frustration number is calculated by just removing the negative signed edges so that each cycle in the graph becomes positive so we obtain balanced signed graph but we select that edges arbitrarily, there is no rule to select such edges. But in single valued signed neutrosophic graph we follow some algorithmic approach to delete such edges. The steps are as follows:
- collect all negative edges

- $\quad$ select edge having minimum membership and maximum non-membership

- remove the selected edge and continue the process till we get all positive cycle in the graph.

For any nodes and edges, we represented truth-membership value by $\mathrm{T}$, indeterminacy-membership value by $\mathrm{I}$ and falsitymembership $\mathrm{F}$ and for any two adjacent positive node following proposition holds good.

Proposition 3.8:- An edge e(T, I, F) joining two positive nodes $\mathrm{u}(\mathrm{T} 1, \mathrm{I} 1, \mathrm{~F} 1)$ and $\mathrm{v}(\mathrm{T} 2, \mathrm{I} 2, \mathrm{~F} 2)$ is positive signed if $\mathrm{T} 1$ $>\mathrm{I} 2$ and $\mathrm{F} 2$ or $\mathrm{T} 2>\mathrm{I} 1$ and $\mathrm{F} 1$.

Proof:- For an edge e $=$ uv, we know $\mathrm{T}=\min \{\mathrm{T} 1, \mathrm{~T} 2\}, \mathrm{I}=$ $\max \{\mathrm{I} 1, \mathrm{I} 2\}$ and $\mathrm{F}=\max \{\mathrm{F} 1, \mathrm{~F} 2\}$ and since nodes are positive thus $\mathrm{T} 1>\mathrm{I} 1$ and $\mathrm{F} 1$ and $\mathrm{T} 2>\mathrm{I} 2$ and $\mathrm{F} 2$. Thus, in this case for positive signed edge, truth-membership value of edge have to be greater than indeterminacy-membership value and falsity-membership value and it is possible only either if $\mathrm{T} 1>\mathrm{I} 2$ and $\mathrm{F} 2$ or $\mathrm{T} 2>\mathrm{I} 1$ and $\mathrm{F} 1$.

Definition 3.9:-The complement of a single valued neutrosophic graph $G=(A, B)$ on $G^{*}$ is a single valued neutrosophic graph $\overline{\mathrm{G}}$ on $\mathrm{G}^{*}$ where

1) $\bar{A}=A$

2) $\overline{T_{A}}\left(v_{i}\right)=T_{A}\left(v_{i}\right), \overline{I_{A}}\left(v_{i}\right)=I_{A}\left(v_{i}\right), \overline{F_{A}}\left(v_{i}\right)=F_{A}\left(v_{i}\right)$, or all $v_{i} \in V$

$$
\begin{gathered}
3) \quad \overline{T_{B}}\left(v_{i}, v_{j}\right)=\min \left[T_{A}\left(v_{i}\right), T_{A}\left(v_{j}\right)\right]-T_{B}\left(v_{i}, v_{j}\right) \\
\overline{I_{B}}\left(v_{i}, v_{j}\right)=\max \left[I_{A}\left(v_{i}\right), I_{A}\left(v_{j}\right)\right]-I_{B}\left(v_{i}, v_{j}\right) \text { and } \\
\overline{F_{B}}\left(v_{i}, v_{j}\right)=\max \left[F_{A}\left(v_{i}\right), F_{A}\left(v_{j}\right)\right]-F_{B}\left(v_{i}, v_{j}\right) \\
\text { for } \operatorname{all}\left(v_{i}, v_{j}\right) \in E
\end{gathered}
$$

Example3.:- An example of Complement of a single valued signed neutrosophic

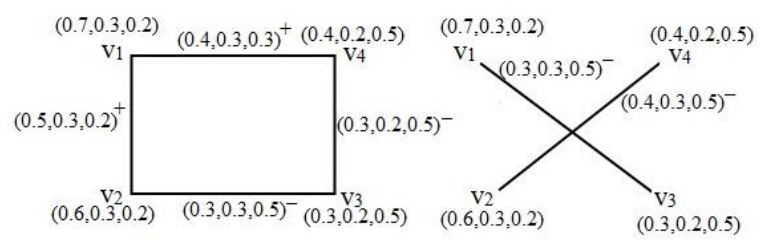

\section{Figure 6 :- Complement of a single valued signed neutrosophic graphs}

Theorem 3.10:- Complement graph of a balanced single valued signed neutrosophic graph is always positive if it is of odd length cycle.

Proof. We know that complement of odd length cycle with $n$ number of nodes is $(n-3)$-regular graph with $n$ number of nodes. Thus for odd $n, n-3$ is always even, so each nodes are connected by even number of edges. Hence for any negative nodes in complement graph there always exist an even number of negative edges whose product is always positive. Hence overall product of sign is always remains positive.

Theorem 3.11:- Complement of a single valued signed neutrosophic path signed graph $\widetilde{P}_{n}$ where $n$ is odd is positive sign graph iff either all nodes or at least end nodes of $\widetilde{P}_{n}$ are negative. 
Proof. As we know that complement of a path graph have $n(n-3) / 2+1$ edges, we may say that complement of path graph with $n$ number of nodes is $(n-3)$-regular with an extra edge between the end nodes. Thus if path $\widetilde{\mathrm{P}_{\mathrm{n}}}$ have odd number of nodes then each node have even degree except end nodes of path $\widetilde{\mathrm{P}_{\mathrm{n}}}$ i.e., sign of complement graph depends upon that extra edge only joins the end nodes of $\widetilde{P_{n}}$, as if end node of $\widetilde{\mathrm{P}_{\mathrm{n}}}$ are negative than its complement graph it becomes positive so the edge associated with it also become positive. Hence the overall multiplication of the signs of all edges in complement of $\widetilde{\mathrm{P}_{\mathrm{n}}}$ is always remain positive.

\section{CONCLUSION}

In this work, we introduced a single valued signed neutrosophic graph In future we can extend this concept to many others neutrosophic graphs and also many properties could be derived.

\section{REFERENCES}

[1] Aydoğdu, On Similarity and Entropy of Single Valued Neutrosophic Sets, Gen. Math. Notes, Vol. 29, No. 1, July 2015, pp. 67-74.

[2] Broumi, S., Talea, M., Bakali, A. and Smarandache, F., Single Valued Neutrosophic Graphs,Journal of New Theory, 2016, 10, 86-101.

[3] Cartwright, D. and Harary, F. , Structural Balance: A generalization of Heiders Theory, Psych. Rev.,1956, 63, 277-293.

[4] Deli, M., Ali, Smarandache , F., Bipolar neutrosophic sets and their application based on multi-criteria decision making problems, Advanced Mechatronic Systems (ICAMechS), 2015 International Conference, 249 - 254, DOI: 10.1109/ICAMechS.2015.7287068.

[5] Gani, N . and Ahamed, M.B., Order and Size in Fuzzy Graphs, Bulletin of Pure and Applied Sciences, 2003,22E (1), 145-148.
[6] Gani, N. and Begum, S.S, Degree, Order and Size in Intuitionistic Fuzzy Graphs, International Journal of Algorithms, Computing and Mathematics, 2010,3(3).

[7] Harary, F., On the notion of balance of a signed graph, Michigan Math. J., 1953, 2(2), 143-146.

[8] Mishra, S.N. and Pal, A. , Intuitionistic Fuzzy Signed Graphs, International Journal of Pure and Applied Mathematics, 2016,106 (6), 113-122.

[9] Nirmala, G. and Prabavathi, S. , Mathematical Models in Terms of Balanced Signed Fuzzy Graphs with Generalized Modus Ponens, International Journal of Science and Research, 2015, 4(7), 2415-2419.

[10] Smarandache , F., Neutrosophic set - a generalization of the intuitionistic fuzzy set, Granular Computing, 2006 IEEE International Conference, 38 - 42,2006,DOI: 10.1109/GRC.2006.1635754.

[11] Smarandache, F. , A geometric interpretation of the neutrosophic set - A generalization of the intuitionistic fuzzy set Granular Computing (GrC), 2011 IEEE International Conference , $602-606,2011$, DOI 10.1109/GRC.2011.6122665.

[12] Smarandache, F., Symbolic Neutrosophic Theory, Europanova asbl, Brussels,2015, 195.

[13] Smarandache, F., Types of Neutrosophic Graphs and neutrosophic Algebraic Structures together with their Applications in Technology, seminar, Universitatea Transilvania din Brasov, Facultatea de Design de Produs si Mediu, Brasov, Romania 2015.

[14] Wang, H. , Smarandache, F. , Zhang, Y. and Sunderraman, R. , Single valued Neutrosophic Sets, Multispace and Multistructure, 2010,4, 410-413.

[15] Zaslavsky, T. , Signed Graphs, Descrete Applied Mathematics, 1982, 4, 47-74. 